\title{
New Foundations: Pseudo-pacification and special liberty as potential cornerstones for a multi-level theory of homicide and serial murder
}

\author{
Professor Steve Hall, Teesside University, UK \\ Professor David Wilson, Birmingham City University, UK
}

\begin{abstract}
Over the past thirty years the industrialised West has witnessed a move towards space, heterogeneity and subjectivity in the criminological study of violence and homicide. Whilst large-scale quantitative studies of the temporal and spatial distribution of homicide continue to provide a broad empirical context, aetiological explanations tend to be based on analyses of the heterogeneous psychological interactions and experiences of individual subjects at the micro-level. However, mid-range studies of the temporal and spatial distribution of perpetrators and victims of homicide between unrelated adults have provided a useful link between the microand macro-levels. Focusing primarily on British homicide and serial murder, this article attempts to strengthen this link by combining contemporary micro-analyses of the subjective motives of perpetrators with mid-range analyses of space, which can therefore be seen as part of the structural tradition of theorising about homicide and serial murder. Placing these analyses in a broad underlying context constituted by major historical shifts in political economy and the cultural forms of 'pseudo-pacification' and 'special liberty' will lay the initial cornerstones for an integrated multi-level theory.
\end{abstract}

\section{Keywords}

Homicide, serial murder, space, victims, subjectivity, special liberty, pseudo-pacification

\section{Introduction}


The principle put forward near the beginning of the era of 'radical' criminology, that we need a 'fully social' theory of deviance (Taylor et al, 1973), now seems inadequate. This was a premature call to present the sum before its parts were fully understood. We now know that we need far more detailed knowledge about those parts. Since then many attempts have been made to break down and integrate 'the social' and its structural relations of class, race, gender and age with other important intersecting dimensions such as historical process, political economy, culture, space, biography and subjectivity. Even biology has made something of a comeback, now in a form that is far more enlightened and sociologically aware than the previous lurches into crude determinism and eugenics that discredited the overall intellectual project (see Owen, 2012; Dickens, 2004).

However, criminology still experiences difficulty in its attempts to construct theories of violence that can integrate the main three analytical levels: micro (subjective/psychological motivations and justifications); meso (local temporal/spatial patterns and cultural norms); and macro (large-scale historical and spatial patterns in underlying socioeconomic, cultural and political contexts). Previous attempts have produced valuable ideas but have tended to be rather one-dimensional. For instance, institutional anomie theory focuses on loss of meaning; differential association and sub-cultural theories focus on reproduction and excess of meaning; control theories focus on loss of control; general strain theory focuses on situational loss of opportunities; psychological theories of motivations focus on individual experiences, and so on (see Lilly et al, 2010; Hall, 2012 for critical sweeps across the canon of criminological theory). Of the classical theories, strain theory was probably the most successful in integrating the three analytical levels, but it lacked an adequate conception of space and inappropriately naturalised the 'malady of infinite aspirations' as the principal condition of subjectivity (Hall, ibid.). Integrated theories, which have been common in 
criminology and sociology since Cloward and Ohlin's (1960) combination of strain, differential association and sub-cultural theories, have produced some very interesting hybrids with potential for further development (see Akers and Sellers, 2004). However, this potential is hampered by the lack of reliable empirical data on all three levels of analysis and the difficulty of constructing concepts that are able to integrate these levels. These concepts are often ontologically specific to each level and the distinct philosophies and politics that underlie each traditional theory (see Hall, ibid.).

Although violence is a broad and slippery concept, empirical studies of homicide are useful as a foundation for theoretical integration. Homicide is one of the fundamental 'consensual crimes' around which hard-line social constructionist explanations collapse to reveal a firmer object for empirical and theoretical attention. The vast majority of homicidal acts are discovered and recorded, thus statistical representations are more reliable than those that represent general crime and violence, which are more susceptible to variations in socially constructed definitions and irredeemably debased by a large estimated 'dark figure' of unreported and unrecorded incidents (Brookman, 2005; D’Cruze et al, 2006). Legal and cultural definitions of homicide are very similar across the nations and regions of the industrialised West, therefore cross-cultural and temporal comparisons of statistical rates can be made with more confidence (Barclay et al, 2003). However, despite the opportunities these relatively reliable data present, outside psychology the aetiological study of homicide nonetheless suffers from 'academic neglect' (Brookman, 2005: 1). As a consequence, questions related to explaining what motivates one human being to kill another human being are seldom considered in their socioeconomic contexts within academic criminology or sociology, despite the popular fascination that this type of question generates. 
Brookman's observation is perhaps even more apt when we consider the relative dearth of academic interest in the phenomenon of serial murder in its socioeconomic contexts (for interesting psychologically-based explorations see: Beasley, 2004; Burgess, Hartman, Ressler, Douglas \& McCormack, 1986; Hickey, 2006; Meloy, 2000; Myers, Gooch, \& Meloy, 2005; Stone, 2001). We employ throughout this article the standard academic and European definition of 'serial murder' as the killing of three or more victims within a period of greater than 30 days (Wilson, 2007) and continue Grover and Soothill's (1999) and Wilson's $(2007 ; 2012)$ attempts to adopt a structural, as opposed to a relentless medicopsychological approach, to this phenomenon.

Previous empirical studies of homicide rates have produced reasonably reliable data on two of the three levels of analysis, the macro and the meso. In European studies the most common representation at the macro-level is the palpable decline in homicide rates that Western Europe experienced throughout the early-modern and modern eras (see Eisner, 2011 for a statistical breakdown). Similar but more undulating declines can also be discerned in the United States of America on a more compressed time-scale from the mid-nineteenth century (see Roth, 2009; Hall and McLean, 2009). Underneath this empirical phenomenon is a complex array of shifting social relations, forms of political economy and cultural norms and values.

We know that fluctuations in statistical homicide rates tend to coexist at specific points in time and space (Currie, 2009). Higher than average rates are found in spatial regions and locales that can be distinguished by their marginal positions in the socioeconomic structure. These positions have changed over time, and the variations follow a discernible pattern (see Hall and McLean, 2009; Marktanner and Noiset, 2013). For instance, there is little doubt that 
since the 1970s, geographical spaces in the deindustrialised regions of Europe and the USA that have returned significantly higher rates of homicide have also suffered from economic disruption, increased unemployment, ethnic tensions, loss of credible political representation, a decline in cultural status, damage inflicted on vital social institutions such as family, housing and education and the growth of criminal markets (Dorling, 2004; Reiner, 2007; Parker, 2008).

However, we still do not know enough about subjective motivations and whether or not they, rather than the opportunities to commit homicide, also vary over time. This is a crucial distinction because the theoretical and political polarity it implies is quite extreme. To suggest that only opportunities vary and there will always be a small number of killers 'out there' waiting to pounce on victims unless intrusive systems of security and protection are rigorously and indefinitely maintained buys into classical liberal and conservative fatalism. Conversely, to suggest that the propensity to kill, and by extension human nature itself, varies over time and space fits with a more optimistic liberal principle of a flexible human nature whose underlying benign orientation to others can be brought to the fore by creating and maintaining more equal and less aggressive underlying socioeconomic and cultural conditions. The difference in the political and policy programmes of general violence reduction suggested by either of these positions is polarised and qualitatively different; increased security and control over an innately errant human nature in a society determined by market forces versus some degree of progressive political intervention in underlying socioeconomic and cultural conditions.

If this crucial question is to be answered, criminology must further its understanding of the subjective micro-level to the extent that it can recognise patterns in the rather daunting 
variety of motivations and justifications that permeate this level, and begin to integrate these patterns more firmly with those already known to constitute the spatial/temporal meso-level and broad historical and structural macro-level. This article will argue that a firm focus on the victim, the victim's socio-cultural relation to the killer and the spaces in which homicide between unrelated adults tends to be committed presents us with a potentially fruitful approach to an integrated theory.

We will focus down further on serial killing, which, although an extreme and relatively rare form of homicide, can reveal specific subjective motivations and underlying cultural currents that are known to be associated with other forms of homicide in Europe and the USA (Wilson, 2007; Stein, 2007). Our overall aim is to make a tentative move towards the construction of a provisional and probabilistic analytical nexus that connects the subjective, spatial and broad structural levels, in the hope that it can inform integrated theory construction in the future. By introducing to the debate the new concepts of pseudopacification and special liberty (see Hall, 2012), which we fully define later, we also hope to propose a very basic outline of what we regard as the fundamental form of cultural mediation that pervades all liberal societies. These concepts will help to establish firmer and more plausible connections between the three analytical levels.

\section{The macro-level: structure, politics and culture}

In Western Europe and the USA there is a long tradition of social scientific macro-analyses of homicide that operate on the broad structural and temporal level. Western Europe seems to be characterised by a long-term decline in rates of homicide, which, depending upon the 
specific region, commenced from various points between the $14^{\text {th }}$ and $16^{\text {th }}$ century and stretched to the mid-20 $0^{\text {th }}$ century (Eisner, 2011), from which point there have been undulating rises in most nations (Hall and McLean, 2009). The US homicide rate, however, has fluctuated in a more spectacular fashion in a condensed time period since the mid- $19^{\text {th }}$ century when reliable data began to be collected, and regional and local differences have tended to be greater (Roth, 2009; see also Monkonnen, 1989; 1997; 2001).

Two very salient theoretical propositions emerge from Roth's (ibid.) broad but regionally differentiated analysis of homicide in the USA, both of which echo Verkko's (1951) classic observations in Europe. Firstly, whereas the rate of intimate homicide tends to be relatively consistent, temporal and spatial fluctuations in the rate of homicide between unrelated adults are significantly more pronounced, and thus seem to present us with a broad empirical framework for theorising significant changes in underlying probabilistic circumstances. Secondly, when all regional differentiations and complications are taken into account, four major forms of broad cultural mediation, which seem to link external circumstances at the macro-level to individuals' interior subjective feelings, motivations and violent actions, correlate with reduced rates of homicide between unrelated adults:

1. The general belief that government is stable, legitimate, representative and capable of protecting the person.

2. An acceptable degree of trust in the individuals who run government and public services.

3. The broad existence of empathy arising from social and political solidarity.

4. The belief that one's position in society is satisfactory, and one can command respect without resorting to violence. 
This cultural framework relates to Elias's (1994) theory of the 'civilizing process', a concept born in his attempt to explain the long-term decline in general brutality and the rise of nonviolent social interaction in Western Europe. This theory sets out the underlying political and sociological prerequisites upon which these mediatory psycho-cultural forms are dependent:

1. A legitimate state that monopolises the right to use violence

2. The maintenance of 'figurations', or a broad network of interdependent and thus friendly and empathetic social relations

3. The maintenance of behavioural codes that insist on civility and non-violent interaction

However, Elias's critics, such as Mucchielli (2010), Ray (2011) and Weiviorka (2009), argue that his set of prerequisites underplays the vital importance of socioeconomic equality, the institutionalisation of welfare and education, and the institutionalisation and resulting pacification of the potentially violent socio-political conflict that characterised Western nations up to World War II. Should these institutional forms malfunction, the maintenance of Elias's three prerequisites is very difficult. Roth (2009: 473) dismisses the 'performance of the economy' as a factor in violence reduction, yet, in the USA and Western Europe, over 90 per cent of homicides occur in locales of socioeconomic disadvantage, and many are associated with some form of economic crime (Hall and McLean, 2009; Marktanner and Noiset, 2013). We suggest that Roth set up a straw target that ignores Durkheim's and Merton's warning that there are no simple economic 'cures' for crime if 'economy' is expressed in such crude material terms (see Hall, 2012). It is not the level of material production but the relative equality of socioeconomic relations - signified not simply by a more even distribution of material products and economic opportunities but also by social solidarity and equality of political participation and cultural status - that should be considered 
as the main macro-factor associated with lower rates of crime and violence (Ray, 2011). Without this, political legitimacy, social stability and interpersonal empathy are less likely, especially in conditions of extreme inequality (Wilkinson and Pickett, 2010; Currie, 1985).

Another important factor alongside equality is stability. Surveys of homicide rates across Europe and North America indicate very clearly that relatively stable social democratic nations such as Sweden and Germany, residual social democracies such as the UK and Canada, and conservative corporatist nations such as Italy and Spain, all experience notably lower rates than unstable deregulated neoliberal societies such as post-1971 USA and postSoviet Russia (Hall and McLean, 2009). In the USA's social democratic period from 1937 to 1980 the homicide rate and general crime rate were cut in half. The homicide rate doubled in 1980 and reached a higher peak in 1991 as neoliberal economics devastated many urban industrial areas and created space for expanded criminal markets, most notably in illegal drug distribution (Currie, 1985). Since the mid-1990s the general crime and homicide rates have been returned closer to those of the social democratic period, but this has been achieved only in the midst of a significant increase in imprisonment rates and supervisory programmes, and huge investments in the therapeutic state - significant numbers of young people inappropriately prescribed Ritalin, Prozac or atypical anti-psychotics (Breggin, 2012) - and in the surveillance and securitisation of public space (Coleman and McCahill, 2011). In the social democratic era, these intrusive pacifying measures were far less prominent yet homicide and overall crime rates were significantly reduced. This reduction occurred as the traditional political struggles that characterised this era temporarily established increased socioeconomic equality, political participation, full employment and publicly-funded welfare, health and education systems. 
Socioeconomic stability, political rights, low crime rates, low incarceration rates and less intrusive forms of surveillance could be seen across the whole of the industrialised West in what Bauman (2000) called the 'golden age' of post-war consensus (see also Reiner, 2007). According to Currie, social democratic politics alleviated many of the primary probabilistic conditions that correlate with high rates of violence and homicide:

[An] especially violent society would surely contain these elements: It would separate large numbers of people, especially the young, from the kind of work that could include them securely in community life. It would encourage policies of economic development and income distribution that sharply increased inequalities between sectors of the population. It would rapidly shift vast amounts of capital from place to place without regard for the impact on local communities, causing massive movements of population away from family and neighborhood supports in search of livelihood. It would avoid providing new mechanisms of care and support for those uprooted, perhaps in the name of preserving incentives to work and paring government spending. It would promote a culture of intense interpersonal competition and spur its citizens to a level of material consumption that many could not lawfully sustain (1985: 278)

Homicide rates also tend to vary across nations, regions and locales that differ in their ability to counteract the cultural factor of intense interpersonal competition with an alternative culture of empathy and solidarity, one of the main reasons 'why some places are more dangerous than others' (Currie, 2009: 4). Nations that have undergone rapid transitions to neoliberal market economies, which caused socioeconomic instability, widening inequality and the intensification of competitive individualism, such as post-Soviet Russia and the 
former Soviet satellite states of Eastern Europe in the 1990s, have also experienced notable increases in crime, homicide and imprisonment rates (Lafree and Tseloni, 2006; Volkov, 1999; Gerber and Hout, 1998). For Currie, the most important generalisable probabilistic factors that consistently fit the evidence are:

1. deep socioeconomic inequality

2. marginal work

3. weak social supports

4. strained families

5. harsh and ineffective criminal justice systems

6. easy access to firearms

Currie's basic schema has been corroborated by numerous quantitative and qualitative studies (see Braithwaite and Braithwaite, 1980; Blau and Blau, 1982; Dorling, 2004; Reiner, 2007; Wilkinson and Pickett, 2010; Ray, 2011; Wilson, 2007; Hall and McLean, 2009; Marktanner and Noiset, 2013). The upshot of this macro-level position is that in periods and spaces where citizens feel poorly represented by their governments and Currie's six conditions also apply, overall rates of homicide, particularly rates of homicide between unrelated adults, are significantly higher. This schema is more expansive, more contextualised and has more sociological depth than Roth's four cultural macro-variable and Elias's three sociopolitical macro-variables. However, other Western nations suffer from socioeconomic instability and spatially distributed inequality and have easy access to firearms, yet they maintain relatively low homicide and imprisonment rates (see Hall and McLean, 2009). To begin to solve this problem we must return to Currie's earlier work $(1985 ; 1997)$, where he suggests that the USA's more intense culture of competitive individualism might be the crucial factor that 
makes simultaneous contributions to its relatively high homicide rate by normalising aggressive human interaction, and to the reproduction of the probabilistic contexts in which this higher rate tends to appear.

Theorists who have attempted to provide simple socio-structural explanations of violence and homicide have been unconvincing. For instance, Connell (1995) points out the fact that public violence tends to be committed by men, and goes on to explain male violence in economically run-down locales as a product of 'protest masculinity', the physical expression of frustrated and inarticulate dissent against the forces that have created political and socioeconomic exclusion. This is simply the uncritical application of the paradigmatic idea put forward by Taylor et al (1973) that violent crime is a misguided form of proto-political dissent. Elliot Leyton (1986) adopts a similar approach in his theory of serial murder, suggesting that since 1945 it has been a form of 'homicidal protest' acted out by frustrated male members of the upper working and lower-middle classes who tend to kill victims from the middle classes. Despite the popularity of this broad theoretical explanation, it simply does not work as an explanation of violence, homicide or serial murder in Britain. Leyton does acknowledge that ' $[0]$ ccasionally ... [serial killers] continue a metaphor from the earlier era and discipline unruly prostitutes and runaways' (1986: 297), but he goes on, '[m]uch more commonly ... they punish those above them in the system - preying on unambiguously middle-class figures such as university women' (ibid.). However, as Grover and Soothill have argued:

The British experience certainly does not confirm the latter aspect of the Leyton thesis. ... the victims of modern British serial killers are not from the relatively powerful middle classes, but are from relatively powerless and vulnerable groups - 
children and young adults; gay men; women (particularly those vulnerable through their work in the sex industry or on account of the breakdown of familial relations); and pensioners. In fact, the general absence of persons from relatively powerful positions is especially noticeable (1999: 12).

It is rare that a sociological analysis is diametrically opposed to the truth. However, recent work by philosophers and social theorists suggests that most acts of serious violence, homicide and serial killing are not misguided proto-political protests but born of conformity to capitalism's 'obscene Real', a term that means the system's functionally active yet systematically disavowed exploitative, predatory and violent drives (see Žižek, 2008; Hall et al, 2008; Hall, 2012). However, even when the possibility of conformity is acknowledged, it is difficult to see this type of illegitimate violence as part of a general 'hegemonic' strategy that functions to maintain a hierarchal social order. Connell (ibid.) points out that systemic violence permeates the current social order, but links the bottom to the top by focusing on the intersecting gender order; all men, she argues, benefit from the 'patriarchal dividend' because the violence they use to maintain dominant positions over women and less aggressive men at various points in the social order is legitimised by patriarchal culture. However, although this can have some purchase as an explanation of domestic violence and other forms of male violence in private spheres, it makes little sense in the public sphere. Firstly, traditional male culture systematically discredits those who inflict violence on more vulnerable individuals (Jefferson, 2002). Secondly, only a minority of men commit acts of serious violence in the public sphere and, thirdly, in largely pacified Western societies, physical violence is ineffective as both a localised and an overall dominance strategy (Hall, 2002). 
Murderers and serial murderers transgress these cultural prohibitions and rationales and therefore fail to conform to traditional masculine or indeed feminine cultural codes. In a culture that is unforgivingly competitive yet legitimises only non-violent, rule-bound aggression in public life, what they do is distinctly anti-hegemonic. While acknowledging Leyton's basic 'structural approach', Wilson (2007), building on the work of Grover and Soothill (1999), quoted above, offers a victim-centred perspective on the phenomenon of serial killing. Specifically, he considers the 375 victims of British serial killers since 1960 and notes that, while most of the victims of male homicide between unrelated adults have been other men (see Hall, 2002), serial killers are different insofar as they have overwhelmingly targeted just five groups in British society: gay men; the elderly; babies and infants; sex workers; and, finally, a group that he describes as 'runaways and throwaways'. Four of these five groups are dominated by women and girls and Wilson argues that the group targeted most frequently by British serial killers are elderly women, just under 70 per cent of victims killed within this time-frame (Wilson, 2007: 55). However, despite these distinguishing factors, there is an interesting structural homology between victims of homicide between unrelated adults and victims of serial murderers - they tend to be vulnerable, from excluded populations and relatively unprotected.

Weiviorka's (2012) claim that we should take the victim perspective more seriously rings true, because it can inform theories of motivation by identifying patterns of offending and illuminating the subjectivities involved in victim-offender relations. Here, the victim's marginalised social position can be brought into clearer relief by relating it to the cultural macro-factor of competitive individualism (Currie, 1985; 1997). Social inequality is the product of a system constituted by various social axes of domination, but, in a liberaldemocratic system, even though that inequality can be reproduced over time by the inherited 
privilege that restricts social mobility, the system is relatively open. The configuration of winners and losers and the spaces they inhabit are the outcomes of an ongoing competitive struggle (Winlow and Hall, 2006; Hall, 2012). If the vulnerable victims of homicide between unrelated adults and methodical predatory killing consistently occupy the position of 'the loser' in this competitive struggle, we need to understand its forms and relations in finer analytical detail.

The concept of competitive individualism is well known in social science, but few analyses have examined its basic rules and internal dynamics. If competitive struggle between individuals for wealth and status is indeed the dominant hegemonic norm in Western societies, although its intensity varies between nations and regions, that same norm demands that the struggle should be acted out in pacified non-violent ways. For us, this indicates that a dynamic tension underlies what Elias described as the 'civilizing process'. The concepts of pseudo-pacification and special liberty will help to explain this tension and further our understanding of the vital cultural macro-variables that attend the socioeconomic and political macro-variables outlined above. The pseudo-pacification process has been explicated in fine detail elsewhere (Hall, 2007; 2012), but here a brief summary will provide some important contextualisation for the long-term empirical decline in homicide that has been a consistent feature of Western Europe.

European Feudal societies were structured by 'righteous violence' (Maddern, 1992), the everyday use of which, in the forms of fatal or seriously injurious punishment or armed assaults, was restricted to the ruling elite. In England, political and economic systems were destabilised after the fall of Rome and again after the Norman invasion. In the aftermath of both disruptive periods systems of monopolisation and legitimisation broke down and the 
social use of violence became chaotic and poorly regulated, which hampered production, property rights and the trading of private property (Ward-Perkins, 2005).

Edward 1's reorganisation of regulation and criminal justice after 1274 reduced rates of violence, enhanced the protection of property rights, and increased the security and therefore the functionality of trading nodes and arteries. Political violence increased the homicide rate in the late 14th century, but after the plague, when expanded economic opportunities in a reduced population were combined with a developing rule of law and the state's monopolisation of serious violence, the rate began its long historical decline. These economic opportunities enhanced social mobility, which, because physical violence was more successfully regulated, was achieved by early forms of entrepreneurialism. This new culture of entrepreneurial individualism was abetted by the introduction of the laws of primogeniture and entail throughout the social structure, which effectively ejected children from the defensive familial/communal unit as soon as they had reached adulthood, thus increasing sentiments of personal anxiety. This cell-like splitting of traditional social units also atomised and expanded libidinal drives, forcing anxiety-driven personal ambition to be democratised and sublimated into a non-violent competition for socio-symbolic status, which was achieved by successful personal performances in markets and displayed by conspicuous consumption.

The English protected property, expanded production and trade and intensified consumer desire by sublimating physical violence, establishing a culture of non-violent yet aggressive sociosymbolic competition amongst atomised individuals and, by loosening up the social hierarchy, encouraging it to diffuse and proliferate throughout the social order. This process took hold over different time-spans in Western Europe, but England's head-start firmly established the culture of pseudo-pacified competitive individualism and eroded traditions of 
collectivism. Although Italian city-states such as Venice were the first in Europe to develop fully-blown commercial activity, most continental European regions, in which the laws of primogeniture and entail applied solely to the ruling class, were forced to deal with higher levels of violence, banditry and other forms of defensive-aggressive collectivism in civil society up to the $16^{\text {th }}$ century and beyond, whilst England's more firmly established pseudopacified culture laid the foundations for an accelerated run-up to industrialisation.

Thus pseudo-pacified behaviour did not establish itself for the sake of some civilizational ideal, nor in the name of some transcendental love of peace and resistance against domination, but to perform the dual function of protecting property rights to enhance trade and creating a pacified form of social competition that fuelled consumer culture and increased demand in burgeoning markets. Over the course of modernity, competitive individualism, shorn of legitimate physical violence yet still aggressive and hierarchal in a more fluid social structure, could be brought to the centre of the socioeconomic system as a dominant cultural norm and dynamic drive. This was not a 'civilizing process', nor even a pacification process, but a pseudo-pacification process established and reproduced as the cultural fuel for economic dynamism. As such, it rendered the pseudo-pacified subject and its non-violent relations with others in a state of tension, over-dependent for its complicity with civilising norms and laws and the constant expansion of opportunities for wealth, expressive hedonism and the achievement of social status by means of conspicuous consumption.

The aristocratic love of libidinal liberty and conspicuous displays of superior status, which Veblen (1994) noticed still alive and well amongst successful entrepreneurs in the late-19 $9^{\text {th }}$ 'gilded age' in the USA and Europe, were diffused and democratised in a competitive socially-mobile entrepreneurial economy and a consumer culture of 'affordable luxury'. 
However, successful entrepreneurs also carried forward the aristocratic sense of privilege and supremacism in a modified cultural form now associated with their commercial activities, which can be captured in the term special liberty (see Hall, 2012). This is a master signifier that legitimises and justifies wealth-creating and expressive activities that often risk harm to others, and establishes a culture of Rousseauean amour propre, in which the individual understands his social status only in relation to the downfall of others (Hall et al, 2008). Although law does not necessarily legitimise the exploitation, negligence, lack of health and safety, environmental degradation, social disruption and so on caused by competitive business enterprise, the constant difficulty law faces in convicting business owners and managers constitutes a 'crisis of enforcement' (Tombs and Whyte, 2008). Special liberty is a condensation of the dark side of liberal individualism (see Fish, 2010), the conviction that the individual, once his high moral and functional importance is established in his own mind, is exempt from social responsibility and can do what he or she wants, even when the gratification of material or expressive interests risks harm to others.

Pseudo-pacification and special liberty together constitute the powerful and historically specific libertarian macro-cultural current that underlies modernity and capitalism. In this current extreme forms of negative freedom (rights) have been institutionalised and democratised to allow extreme forms of positive freedom (desires) to flourish and fuel consumer markets. The resulting dynamism is economically potent yet psychologically, culturally and socially unstable, and therefore requires sophisticated and intrusive forms of external securitisation to keep its restless forces in check (Hall, 2012; see also Crogan, 2010). An understanding of this cultural current allows us to understand the complex dynamics that constitute and energise the Western form of competitive individualism and make another important macro-correlation. Namely, that Western nations, regions and locales in which this 
macro-cultural current is especially powerful, opportunities for expressive hedonism and social advancement are relatively sparse, and in which mechanisms of informal control and formal securitisation and protection are under constant strain - such as the USA and Russia in the neoliberal era - suffer from high rates of homicide and spates of serial killing (Wilson, 2007; Holmes and DeBurger, 1988; Holmes and Holmes, 1994; Fox and Levin, 2005).

\section{The meso-level: locale and situation}

To develop these macro-level correlations, processes and concepts into a tentative multi-level theory of causation they must be connected to the meso- and micro-levels. Social scientists are aware that social inequality and the other macro-variables identified above fluctuate across time and are distributed across space as well as the standard social axes of class, gender, ethnicity and age. Dorling's (2004) research in Britain echoes that of Parker (2008) in the USA. Parker reminds us that after the US homicide rate reached $20^{\text {th }}$ century peaks in 1980 and 1991 it entered a period of decline from the mid-1990s, alongside the general statistical crime rate. However, this decline, just like the sharp rises between the mid-1970s and early 1990s, was unevenly distributed across space. Across the West relatively poor, rundown deindustrialised zones continued to return homicide rates consistently higher than the national average (see Dorling, 2004; Reiner, 2007).

In economically unstable and culturally competitive neoliberal economies the macrovariables, outlined above, which are essential to the maintenance of non-violent interpersonal relations, are all eroded at the macro-social level (Hall, 2007; Wilson, 2007). However, this erosion can be extreme in specific run-down regions and locales. An analysis of the 
autotomic production of space (Atkinson and Parker, 2011) can help to connect macrovariables to the micro-variables that relate to both homicide and serial killing.

One-off killers, serial killers and those who commit various acts of serious violence that incur substantial penalties all want to avoid the consequences of detection. The deterrent effect of the public gaze - whether the conduit is technological surveillance, the presence of police and security staff or simply the presence of other people - can to some extent reduce acts of murder, serious violence and altercations or risky activities that can lead to manslaughter and other forms of accidental death (Hobbs et al, 2003). However, serial killers, driven to act out extreme forms of hatred and rage, which, as we will explore in detail later, are the products of their biographical experiences (Bollas, 1995; Stein, 2007), do not want fully and permanently to gratify their drives and desires because that would allow them to become satiated. Rather, they want to retain the chance of acting them out as many times as possible in the future. Although we would support the claim that homicide in private spaces, such as the domestic household, requires its own specialised research agenda, a common function shared by the private and public space can still be discerned. Namely, that specific types of public space, like all private spaces, are conducive to the prolonged concealment of acts of violence.

All killers operate in three major spaces. While rates of intimate homicide in private spaces tend to be consistent (Roth, 2009), interesting temporal and spatial variations can be found in rates of homicide between unrelated adults in the two other forms of public space: the liminal space, in which the killer can find victims and 'hide in the light'; and what Papastergiadis and Rogers (1996) call the parafunctional space, which provides both victims and prolonged concealment. While some urban spaces are vibrant (see Campbell, 2012), parafunctional space is 'dead space', which no longer performs its appropriate function. However, the 
important commonality is that these two spaces represent the opposite of discipline (Hayward, 2012). A large proportion of urban economic and political activity is simply an effort to prevent spaces becoming parafunctional, or perhaps whole urban areas becoming 'ghost towns', a fate that threatens large sectors of once major commercial and manufacturing cities such as Detroit in the USA or Liverpool in the UK. Hayward (ibid.) is correct that more control and surveillance cannot bring parafunctional spaces back to life, but more pertinent here are the processes that create and reproduce these spaces. Atkinson and Parker refer to the autotomic production of space as:

[T] he social, political and economic processes through which the costs of maintaining 'unruly' space and state and civil exposure to risk bearing agents are mitigated through spatial abandonment and rejection. Prominent examples of such spatial practices include policing 'no-go' areas (high crime and social disorder zones), urban wastelands, derelict buildings, public transport 'misery lines' and those spaces tacitly understood to be under informal curfew (2011: 2).

For Atkinson and Parker, the state and private sector together construct these spaces by practices of social division and expulsion but, more importantly, the mode of control is managed through the primary practice of disengagement and the concomitant preferential protection of the more salubrious spaces inhabited by higher income groups. This formulation presents an alternative to the largely obsolete 'panopticon' and 'net-widening' discourses that still remain popular in criminology. Control is exerted preferentially, which leaves the autotomic space amputated from the social body, unattended and unprotected, a shadowworld in which unseen and unregulated activities can take place. The irony is that this autotomic method of control exacerbates the problem of the uncontrollable space; it is a 
method of what we might call stringent quarantining, shorn of any ethical or even commercial ambitions of reform or redevelopment, and the quarantined space is simply cast into the shadows. In a nutshell, the autotomic process is a process of exfoliation, shedding and abandoning a former part of the urban social body that can no longer be commercially exploited or socially controlled. The quarantined parafunctional space is by its nature lifeless, disconnected from the urban rhizome until such time that people move in to occupy it, such as refugees and immigrants breathing new economic, social and cultural life into abandoned or partially abandoned and run-down residential areas.

However, many urban spaces can verge on the parafunctional by day but adopt the role of the vibrant liminal space by night - the night-time economy. It is rather counter-intuitive to suggest that the abandoned, unattended space and the frenetic, hedonistic liminal space have a common characteristic, but of course they share two important properties. Firstly, both are resistant to surveillance and therefore offer the potential of anonymity and a relative lack of protection for their inhabitants. Secondly, this lack of protection introduces an important complementary variable; the increased availability of victims. Perpetrators of serious violence, homicide and serial murder take advantage of the vulnerable individuals who can be found in the unprotected spaces created by capitalism's periodic bouts of creative destruction. For Winlow and Hall (2006), the British night-time economy is a commercial liminal space in which competitive individualism, hostility and violence have become normalised as the dark side of alcohol-fuelled fun and hedonism, and over 90 per cent of violent acts go unreported and unrecorded. Wilson (2012) points to spaces that exist in a surreal hybrid interface between the parafunctional space and the commercial liminal space. These rundown yet paradoxically vibrant and hedonistic spaces suffer from a lack of guardianship, as 
the situational crime prevention theorists would have it, but, more importantly, they also act as a principal attractor and arena for predator and victim alike.

Wilson et al (2010) discuss the example of Trevor Joseph Hardy, one of a number of British serial killers who operated in this hybrid space. Hardy murdered three teenage girls between 1974 and 1976 in an area of Manchester that was described at the time as "economically deprived', which may have contributed to the lack of attention paid to Hardy's case. In short, several serial killers and their crimes belie Haggerty's (2009: 174) claim that they are 'readymade for prime-time'. They also belie the orthodox criminological position which claims that criminology and the media are interested solely in the conservative/classical liberal agenda of individual violence. Hardy is a serial killer of three teenage girls whom he did not know. His crimes, victims and personal life - he even had a female accomplice and mutilated his victims' bodies like the infamous 'moors murderer' Ian Brady - should fulfil all the requirements of 'newsworthiness', yet he was almost completely ignored; he was and remains 'unseen'. Wilson et al (ibid.) explain this by noting that Hardy's victims were murdered in a downmarket 'night-time economy' zone in a run-down former manufacturing region in Northern England, an example of the hybrid liminal and parafunctional space where violence is normalised. Because the victims were not prostitutes and therefore lacked a common identity that could be used as a hook, the police and the media were slow to make connections between the murders and therefore the killer was allowed to prolong his concealment.

For over four decades criminology has been focused on the media's sensationalism and concomitant exaggeration of crime rates. Yet Hardy's case is one amongst a number of British serial murders - such as those committed by Kenneth Erskine, Peter Moore and Mark 
Martin - homicides and assaults in hybrid parafunctional/liminal zones that are consistently ignored by the media. Even the more spectacular of these incidents are only briefly mentioned in local news and rarely filter through to the national level, which would suggest that such violence is constantly understated in the public eye. Wilson $(2007 ; 2012)$ points to a vital aspect of the overall multi-level process: hybrid parafunctional/liminal spaces, the mesolevel products of political, economic and cultural macro-forces operating at the macro-level, are public locations where violence and homicide are normalised and predators, products of individual experiences at the micro-level, can meet vulnerable victims whilst drawing minimal attention to themselves and their acts of violence.

\section{Integrating the micro-level: subjectivity in context}

Homicide between unrelated adults in public spaces, despite the disproportionate harm and fear it causes, is still very much a minority pursuit (Hall, 2012). The tendencies that seem to exist amid our probabilistic conditions are built upon relatively small numbers of incidents. Although many individuals experience difficult lives in dysfunctional or abusive families and impoverished socioeconomic environments, only a small proportion of these individuals commit acts of homicide. No move towards an integrated theoretical framework is therefore possible unless the complex issue of subjectivity and its relation to violence and homicide is unpacked. The sociologist Michel Weiviorka (2009) has performed a valuable service to this integrative project by analysing decades of empirical and theoretical work to provide social science with a preliminary typology of the forms of violent subjectivity that operate in various micro-spaces. The following motivations and justifications seem to crop up consistently as ideal-types across the broad spectrum of violent acts, especially homicide: 
1. hypersubjectivity, the product of an overload or a plethora of meanings

2. desubjectivated non-subjectivity capable of surrender to the banality of evil

3. socially liberated antisubjectivity orientated to cruelty, sadism and violence as ends in themselves

4. subjectivity aimed at conserving its being or its foundation

This typology bears some resemblance to the standard but contested psychological typology often used to explain serial killers and other types of methodical killer: visionary, mission, hedonistic/sadistic, power/control (Wilson, 2007; 2012; Holmes and DeBurger, 1988) insofar as they also revolve around the basic desires to establish meaning, destroy meaning or unleash aggressive/sexual libidinal drives without restraint. Bollas (1995), Stein (2007) and Dews (2008) argue that these motivations and justifications for violence have common roots in an absence of trust in the outside world and a loss of empathy felt toward the individuals who populate it, usually the result of severe traumas experienced in the early years of abusive and/or negligent childhoods. However, Stein's (ibid.) research amongst violent prison inmates suggests that the difference between the subjective motivations behind harmful crime, non-fatal violence, fatal violence and methodical fatal violence could be a matter of scale rather than qualitative difference (see also White, 2004). Despite nuances that differentiate various subjectivities and situations, the willingness of, say, the state functionary or corporate criminal to act in ways that risk harm to others in order to gratify material or expressive interests is the same fundamental motivation that drives the methodical killer (Hall, 2012). 
Therefore, what at first glance looks like an impossibly diverse disarray of idiosyncratic subjective motivations does, it seems to us, have some rough underlying shape. Of course subjective motivations and justifications are still pluralistic and complex, and thus extremely difficult to research. Conceptual difficulties are compounded by methodological difficulties such as the inability or reluctance of killers and serial killers to articulate and disclose personal motivations and justifications (Wilson, 2007). However, if we hold on to the epistemological lifeline thrown to us by the basic but still quite useful adumbrated typology outlined above, we might be able to at least begin to connect the predominant subjective forms it identifies with the meso- and macro-levels.

It is well-known that most killers and perpetrators of serious violence have deeply disturbed personal backgrounds. Stein's (2007) research with prisoners shows that over 80 per cent of the prison inmates who had been convicted of fatal and non-fatal violent offences disclosed some degree of neglect and/or abuse during early childhood. Dews (2008) and Bollas (1995) argue that the young child's experience of abuse and neglect from primary care-givers induces a trauma that results in a complete breakdown of trust at the micro-level. Winlow and Hall's (2009) research amongst violent young men in deindustrialised regions makes the link between individual trauma and its cultural reproduction. As localised behavioural codes and institutions of mutual support have largely disintegrated, the individual represses and stores traumatic and humiliating events in the memory. Mistrusting the words and actions of all others with a compulsion that borders on paranoia, he constantly seeks to incite shadowevents - in the vernacular, the individual 'looks for trouble' - in order to release the impotent rage that was produced by his inability to act against the initial, formative acts of abuse committed against the self (see also Winlow, 2012). Similarly, Stein (ibid.) proposes a scalar model of violent dispositions, which suggests that when the initial trauma is extreme and/or 
protracted it produces a dissociated self which simply seeks to by-pass cognition and moral codes to constantly act out the rage that has been inculcated at its neurological core.

The biographical and psychological process that produces trauma and violent dispositions resonates with Roth's work on the decline of trust at the macro-social and macro-political level, a relationship that is so directly analogous that it has often been missed in mainstream analysis, which tends to depict killers as aberrations, departures from the norm. However, a handful of theorists have also made this connection. Stiegler (2009), for instance, comments on the journal of French spree killer Richard Durn, an environmental activist who murdered eight people in his local town hall. Durn attacked bureaucrats because he regarded the current capitalist world as so pan-negligent, abusive and de-collectivised that it could no longer recognise individuals, who consequently struggle to recognise their own existence. Stiegler (ibid) suggests that this relation of non-recognition has moved beyond everyday mistrust to an irretrievable breakdown of the relationship of trust and recognition between the individual and the collective in hyper-individualised late-capitalist societies (see also Honneth, 1996; Yar, 2012; Hall, 2012).

In a similar vein, a cluster of theorists have suggested that the serial killer - the most methodical, instrumental and compulsive of the homicidal types - is not an aberration but the purest and most extreme embodiment of the abusive, negligent and exploitative relationship between the capitalist socioeconomic system and the individual. Haggerty (2009) argues that modernity provides the institutional frameworks, motivations and structure of opportunities for serial killing, whilst Seltzer (1998) similarly posits the killer as an individual who hyperidentifies with capitalism's underlying drives, logics and relations of exploitation. Duclos (1998) portrays the serial killer as the pure and unrestrained subjective embodiment of 
Western nations' centuries of domination. This is an individual born of the untrammelled will-to-power, whose life is a quest to circumvent the symbolic order's prohibitions in the quest for special liberty, the conviction that one is entitled to act out all pressing drives and desires, no matter how extreme, antagonistic and potentially harmful they might be (Hall, 2012).

The upshot of this set of theories is that the serial killer cuts through everyday hypocrisy to act out a pure manifestation of the pre-symbolic human drives - envy, fear, prejudice, hatred, sadism, hedonistic pleasure - that fuel the systemic violence of the socioeconomic system and its attendant culture of special liberty. Thus it is an extreme scalar form of normality, the hyper-normal, more perfectly in tune with the system's hidden obscene drives of violence, negligence and exploitation, which are fetishistically disavowed in public life yet experienced by the serial killer first-hand in early life. As the extreme point on the typographical scale of killers, the serial killer, alongside the more spectacularly brutal one-off killers and spree killers, are all individualised and portrayed as unique aberrations, abnormalities in an otherwise benign system populated by morally upright citizens. Yet all of us, as citizens, as Žižek $(2008 ; 2010)$ reminds us, pursue our livelihoods and our security on the back of the most horrific acts of organised military violence, the disruption of settled economic structures, the systematic exploitation of relatively powerless and vulnerable individuals in industrial processes and the negligence of those whose who are no longer required.

This extreme 'abnormal' figure, as presented by the media, performs the important dual function of distracting attention away from systemic violence and absolving everyday people of any blame they might feel over their role in perpetuating it (Žižek, 2008; Taylor, 2010). In this general discourse the serial killer is distinguished from the one-off killer - and, at a far 
greater distance, from the everyday individual - only by the unusual strength of the dual drive. This drive seeks, firstly, to act out personal hatred of a dismembered and abusive social collective with which he cannot identify. Secondly, it seeks to act out its hyper-conformity with the system's exploitative core drives, which are unleashed by an over-identification with the elite cultural value of special liberty that allows the individual to transcend the normative restrictions set by the pseudo-pacification process. The relatively rare occasions when serial killers are women, who in a traditionally sexist culture occupy a symbolic position of passivity, can be portrayed as even more aberrant and thus present the media with enhanced opportunities for ideological distraction and absolution.

\section{Conclusion}

At the moment the formal and aetiological connections between the three analytical levels we have outlined still remain too tenuous and speculative. To make further progress criminology must embark on a research programme to produce further empirical evidence at all levels and tighten up provisional theoretical concepts with the ambition of constructing a coherent theoretical framework. This is especially true of criminology's current (lack of) theorising related to serial murder in its political, socioeconomic and cultural contexts. However, previous research and theoretical works within a structural tradition have produced initial ideas that are taking shape in the murk that confronts us.

Empirical studies at the macro-level present us with enough discernable evidence of the correlations between temporal and spatial patterns of socioeconomic marginalisation and high 
levels of homicide between unrelated adults to put forward a probabilistic relationship with some confidence. Alongside the well-known factors discussed above we must place the crucial macro-cultural factor of variations in the intensity of competitive individualism. At the meso-level of localised space existing in specific periods of time, the autotomic production of space provides specific local environments within larger socioeconomically marginalised areas where violent offenders can find vulnerable victims and attempt to conceal their crimes. In parafunctional spaces, liminal spaces and their hybrid forms, which are defined by the absence of effective surveillance and control, perpetrators of violence, homicide and serial murders can increase their chances of avoiding attention for long periods of time.

At the subjective micro-level, whilst we support Weiviorka's (2009) request to acknowledge the diversity of individuals' experiences, we suggest that a clear aetiological pattern in the formation of types of subjectivity associated with the more brutal and methodical forms of public homicide can nonetheless be identified. The majority of perpetrators experience traumatic abuse and/or neglect in early childhood. The subsequent breakdown of trust in the other individuals who constitute the collective fuels hatred. This hatred can exist in a latent form at the macro-level, but the real acting out of repressed rage requires extreme abuse and the individual's additional over-investment in the cultural form of special liberty. Therefore, this brutal unleashing of drives in concealed public spaces in the socioeconomic margins does not appear to be an aberration but an extreme individualised manifestation of the lack of trust and brutality that underlie the unforgivingly competitive Western capitalist system. At its cultural and psychosocial heart this system is driven by a pseudo-pacification process, a specific form of competitive individualism whose systemic violence and exploitation are 
concealed by ideological public media discourses and disavowed by citizens who indirectly benefit from their functional presence.

Overall, in Western industrialised nations we can see clear patterns relating to the more brutal and methodical forms of homicide between unrelated adults at all three levels of analysis the macro, meso and micro - which have been extensively researched in the recent past. The difficulty we face lies in constructing adequate analytical connections between the three levels and thus laying the foundations for an integrated theoretical framework. What we have presented here are two new concepts - pseudo-pacification and special liberty - that represent what look like mutually reinforcing processes and forms that constitute dynamic relations between the three levels, and, with further empirical research and theoretical finetuning, could potentially be used as cornerstones in such a project.

\section{Bibliography}

Akers, R.L. \& Sellers, C.S. (2004) Criminological Theories: Introduction, evaluation and application, $4^{\text {th }}$ edition. Los Angeles: Roxbury

Atkinson, R. \& Parker, S. (2011) 'The Autotomic City: The Strategic Ejection of Unruly Urban Space', International RC21 conference on Urban Order, Crime and Citizenship Amsterdam $7^{\text {th }}-9^{\text {th }}$ July 
Barclay, G., Tavares, C., Kenny, S., Siddique, A. \& Wilby, E. (2003) International comparisons of criminal justice statistics 2001. London: RDS Communications and Development Unit, the Home Office

Bauman, Z. (2000) Liquid Modernity. Cambridge: Polity Press

Beasley, J.O. (2004) 'Serial Murder in America: Case Studies of Seven Offenders', Behavioral Sciences and the Law, 22: 395-414

Blau, J.R. \& Blau, P.M. (1982) 'The Cost of Inequality: Metropolitan Structure and Violent Crime', American Sociological Review, 47(1):114-129

Bollas, C. (1995) Cracking Up. London: Routledge

Braithwaite, J. \& Braithwaite, V. (1980) 'Effect of Income Equality and Social Democracy on Homicide', British Journal of Criminology, 20(1): 45-53

Breggin, P.R. (2012) Psychiatric Drug Withdrawal: A Guide for Prescribers, Therapists, Patients and their Families. New York: Springer

Brookman, F. (2005) Understanding Homicide. London: Sage

Burgess, A.W., Hartman, C.R., Ressler, R.K., Douglas, J.E. \& McCormack, A., (1986) 'Sexual Homicide: A Motivational Model', Journal of Interpersonal Violence, 1: 251-272 
Campbell, E. (2012) 'Landscapes of Performance: Stalking as choreography' Environment and Planning D: Society and Space, 30(3): 400-417

Cloward, R. \& Ohlin, L. (1960) Delinquency and Opportunity. New York: Free Press

Coleman, R. \& McCahill, M. (2011) Surveillance and Crime. London: Sage

Connell, R. (1995) Masculinities. Cambridge: Polity

Crogan, P. (2010) 'Knowledge, Care and Transindividuation: An Interview with Bernard Stiegler', Cultural Politics, 6(2): 157-70

Currie, E. (1985) Confronting Crime: An American Challenge. New York: Pantheon

Currie, E. (1997) 'Market, crime and community: Toward a mid-range theory of postindustrial violence', Theoretical Criminology, 1(2): 147-72.

Currie, E. (2009) The Roots of Danger: Violent crime in global perspective. Columbus: Prentice Hall

D’Cruze, S., Walklate, S., \& Pegg, S. (2006) Murder. Cullompton: Willan

Dews, P. (2008) The Idea of Evil. Oxford: Blackwell

Dickens, P. (2004) Society and Nature. Cambridge: Polity 
Dorling, D. (2004) 'Prime Suspect: Murder in Britain', in Hillyard, P., Pantazis, S., Tombs, S. \& Gordon, D. (2004) Beyond Criminology: Taking harm seriously. London: Pluto Duclos (1998) The Werewolf Complex: America's fascination with violence. Oxford; Berg Eisner, M. (2011) 'Killing Kings: Patterns of Regicide in Europe, 600-1800’, British Journal of Criminology, 41: 618-638

Elias, N. (1994) The Civilizing Process. Oxford: Basil Blackwell

Fielding, N., Clarke, A. \& Witt, R. (eds.) (2000) The Economic Dimensions of Crime. London: Macmillan

Fish, S. (2010) The Fugitive in Flight: Faith, Liberalism and Law in a Classic TV Show. Pennsylvania: University of Pennsylvania Press

Fox, J. \& Levin, J. (2005) Extreme Killing: Understanding Serial and Mass Murder. Thousand Oaks, Ca.: Sage

Gerber, T.P. \& Hout, M. (1998) 'More Shock than Therapy: Employment and income in Russia, 1991-1995', American Journal of Sociology, 104: 1-50

Grover, C., \& Soothill, K. (1999) 'British Serial Killing: Towards a Structural Explanation', The British Criminology Conferences: Selected Proceedings, Vol. 2 available at: www.lboro.ac.uk/departments/ss/bccs/vol02/08/GROVEHTM 
Haggerty, K. (2009) 'Modern Serial Killers', Crime Media Culture, 5(2): 168-187

Hall, S. (2002) 'Daubing the Drudges of Fury: Men, violence and the piety of the hegemonic masculinity thesis', Theoretical Criminology, 6(1): 35-71

Hall, S. (2007) 'The Emergence and Breakdown of the Pseudo-Pacification Process', in K. Watson (ed.) Assaulting the Past, Newcastle upon Tyne: Cambridge Scholars Press

Hall, S. (2012) Theorizing Crime and Deviance: A New Perspective. London: Sage

Hall, S., Winlow, S. \& Ancrum, C. (2008) Criminal Identities and Consumer Culture: Crime, exclusion and the new culture of narcissism. London: Willan/Routledge

Hall, S. \& McLean, C. (2009) 'A Tale of Two Capitalisms: Preliminary spatial and historical comparisons of homicide rates in Western Europe and the USA', Theoretical Criminology, 13(3): 313-339

Hayward, K. (2012) 'Cultural Geography, Space and Crime’, in Hall, S. \& Winlow, S. (eds.) New Directions in Criminological Theory. London: Routledge

Hickey, E.W. (2006) Serial Murderers and their Victims. CA: Thomas Wadsworth 
Hobbs, D., Hadfield, P., Lister, S. \& Winlow, S. (2003) Bouncers: Violence and governance in the night-time economy. Oxford: Oxford University Press

Holmes, R. \& DeBurger, J. (1988) Serial Murder. Newbury Park, Ca.: Sage

Holmes, R. \& Holmes, S. (1994) Profiling Violent Crimes. Thousand Oaks, Ca.: Sage

Honneth, A. (1996) The Struggle for Recognition: The Moral Grammar of Social Conflicts. Cambridge: Polity Press

Jefferson, T. (2002) 'Subordinating hegemonic masculinity’, Theoretical Criminology, 6(1): $63-88$

Lafree, G. \& Tseloni, A. (2006) 'Democratizaton and crime: a multilevel analysis of homicide trends in 43 nations', Annals of the American Academy of Political and Social Science, 605: 26-49

Leyton, E. (1986) Hunting Humans. The Rise of the Modern Multiple Murderer. Toronto: McClelland and Stewart

Lilly, J.R., Cullen, F.T. \& Ball, R.A. (2010) Criminologicasl Theory: Context and Consequences. London: Sage

Maddern, P. (1992) Violence and Social Order: East Anglia 1422-1442. Oxford: Oxford University Press 
Marktanner, M. \& Noiset, L. (2013) 'Social versus conservative democracies and homicide rates', International Journal of Social Economics, 40(4): 292-310

Meloy, R. (2000) 'The Nature and Dynamics of Sexual Homicide: An Integrative Review', Aggression and Violent Behaviour, 5: 1-22

Monkonnen, E. (1989) 'Diverging Homicide Rates: England and the United States, 18501875', in Gurr, T.R. (ed.) Violence in America, Vol 1: The History of Crime. Newbury Par, Ca.: Sage

Monkonnen, E. (1997) 'Homicide over the Centuries', in Friedman, L.M. \& Fisher, G. (eds.) The Crime Conundrum: Essays on Criminal Justice. Boulder, Colo.: Westview Press Monkonnen, E. (2001) Murder in New York City. Berkeley: University of California Press Mucchielli, L. (2010) 'Are We Living in a More Violent Society? A Socio-historical Analysis of Interpersonal Violence in France, 1970s-Present', British Journal of Criminology, 50(5): 808-29

Myers, W.C., Gooch, E., \& Meloy, R. (2005) 'The Role of Psychopathy and Sexuality in a Female Serial Killer', Journal of Forensic Science, 50: 1-6

Owen, T. (2012) 'The biological and the social in criminological theory', in Hall, S. \& Winlow, S. (eds.) New Directions in Criminological Theory. London: Routledge 
Papastergiadis, N. \& Rogers, H. (1996) 'Parafunctional Spaces', in Stathatos, J. (ed.) Art and the City. London: Academy Group

Parker, K. F. (2008) Unequal Crime Decline: Theorizing race, urban inequality and criminal violence. New York: New York University Press.

Ray, L. (2011) Violence and Society. London: Sage

Reiner, R. (2007) Law and Order: An honest citizen's guide to crime and control.

Cambridge: Polity

Reiner, R. (2000) 'Crime and Control in Britain', Sociology, 34(1): 71-94.

Roth, R. (2009) American Homicide. Cambridge MA: Harvard University Press

Seltzer, M. (1998) Serial Killers: Death and life in America's wound culture. London: Routledge

Stiegler (2009) Acting Out. Stanford CA: Stanford University Press, trans. D. Barison, D. Ross \& P. Crogan

Stein (2007) Prologue to Violence: Child Abuse, Dissociation and Crime. Mahwah, NJ: The Analytic Press 
Stone, M. H. (2001) 'Serial Sexual Homicide: Biological, Psychological and Sociological Aspects', Journal of Personality Disorders, 15: 1-18

Taylor, I., Walton, P. \& Young, J. (1973) The New Criminology: For a social theory of deviance. London: Routledge and Kegan Paul

Taylor, P.A. (2010) Žižek and the Media. Cambridge: Polity

Tombs, S. \& Whyte, D. (2008) 'A Crisis of Enforcement: the decriminalisation of death and injury at work', London: Centre for Crime and Justice Studies, 1746-6938 http://www.crimeandjustice.org.uk/opus685/crisisenforcementweb.pdf

Veblen, T. ([1899] 1994) The Theory of the Leisure Class. London: Penguin

Verkko, V. (1951) Homicides and suicides in Finland and their dependence on national character. Copenhagen: G.E.C. Gad

Volkov, V. (1999) 'Violent Entrepreneurship in Post-Communist Russia', Europe-Asia Studies, 51: 5 741-754

Ward-Perkins, B. (2005) The Fall of Rome and the End of Civilization. Oxford: Oxford University Press

Weiviorka, M. (2009) Violence: A new approach. London: Sage

Weiviorka, M. (2012) 'From social order to personal subject: a major reversal', in Hall, S. \& 
Winlow, S. (eds.) New Directions in Criminological Theory. London: Routledge

White, G. (2004) 'Political apathy disorder: proposal for a new DSM diagnostic disorder', Journal of Humanistic Psychology, 44: 47-57

Wilkinson, R. \& Pickett, K. (2010) The Spirit Level: Why equality is better for everyone. London: Penguin

Wilson, D. (2007) Serial Killers: Hunting Britons and their victims, 1960-2006. Winchester: Waterside Press.

Wilson, D., Tolputt, H., Howe, N. \& Kemp, D. (2010) 'When Serial Killers Go Unseen: The Case of Trevor Joseph Hardy', Crime Media Culture, 6(2): 153-167

Wilson, D. (2012) 'Late capitalism, vulnerable populations and violent predatory crime', in Hall, S. \& Winlow, S. (eds.) New Directions in Criminological Theory. London: Routledge

Winlow, S. (2012) 'All that is sacred is profaned: towards a theory of subjective violence', in Hall, S. \& Winlow, S. (eds.) New Directions in Criminological Theory. London: Routledge

Winlow, S. \& Hall, S. (2006) Violent Night: Urban leisure and contemporary culture.

Oxford: Berg

Winlow, S. \& Hall, S. (2009) 'Retaliate First: Memory, humiliation and male violence', Crime, Media, Culture, 5(3): 285-304 
Yar, M. (2012) 'Critical Criminology, Critical Theory and Social Harm', in Hall, S. and Winlow, S. (eds.) New Directions in Criminological Theory. London: Willan/Routledge

Žižek, S. (2008) Violence: Six sideways reflections. London: Profile Books

Žižek, S. (2010) Living in the End Times. London: Verso 